\title{
美國科學篇壟溦勢力與軍國主義者服務
}

\section{魯霓斯坦作 高迺賢譯}

美國州版物最近大談其科學在美國的 L獨芒 7 與 中江7阔題，似乎科學是處於政治以外的。然而

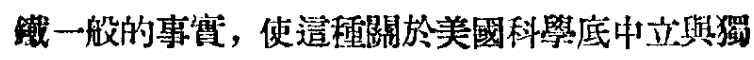
立的胡說, 像烟萦般地消散了。科學, 在美國正充 當着使科學軍國主義化的反動勢力和資本主義壟 断等力底馿服的工具, 以使其服務於自己的侵略 目的,是解谷朋斯了。

在美國 科學㸴究 網底非常龍雜和混 乳情形 下,其中可分成三做基本的、有决定性的集團：工 業托捒斯底科學研究:實驗所、各大學還有各國立

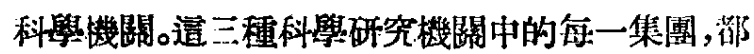
是完全作附於資本主義熊斷樊力，低附於在美國 佔梳治地位的金融資本底政策。

我們拿工業托辣斯底科學實驗所一例來看。

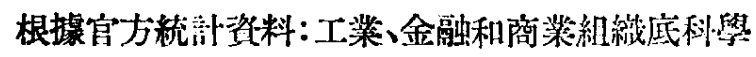
研究機構，在戰前紏合了過牛數的美國全澧科學 研究工作人員; 而其耗貿在科學研究工作上的款 項, 在一九三八年读佔全國科學總額的百分之七 十以上。

由此可見,遠在第二次世界大戰以前,美國科

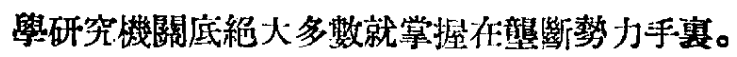

在第二次世界大戰年份, 美國壟斷勢力對於 科舉的統治,是更斯卯虽了。

驡斷勢力掌握科學,首先的目的就是: 把科學 技術上的進步,掌握在自己的手裹,依照自己的意 志亚適應自己的掠㹁利谷來領導和利用它 (而且 常常是故意不去利用)。壟斷勢力這樣地力圖 L破

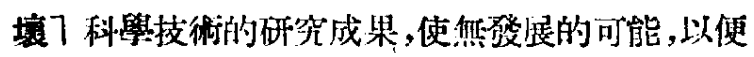
易於獲取超額利潤，並在另一-方面湏防固资资資本 跌落的成㳯。如 L通用汽車公司７汽車托辣斯在生 產中㮖利用了:其操持的專利權的百分之一(!), 而

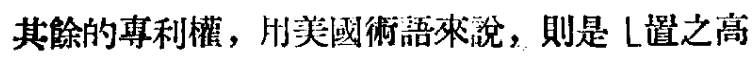
閣7, 既不隼用於自己的企業, 世不予他人以利用 的可能, 祇要指将這一事實, 例證就供够了。

哥倫此亞大學㸚投羅伯爾特・林德對於美國

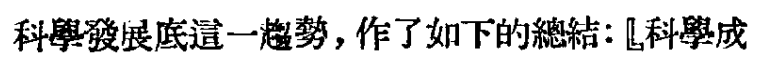

了威力的湏泉。少數的負指導責任的學者䠶完成 其作業,統治我們社会的驡斷勢力, 即付給他們以

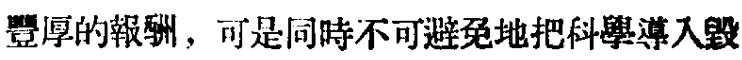
減的前途》。

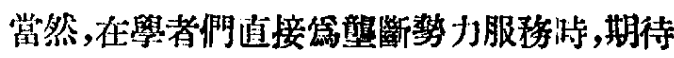

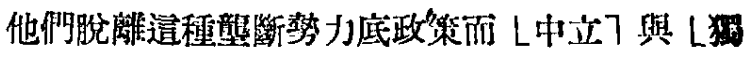

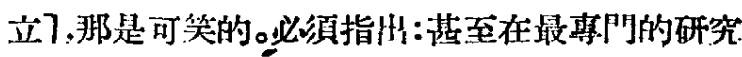

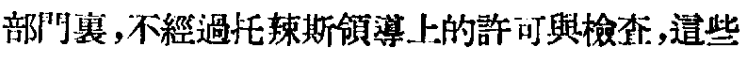

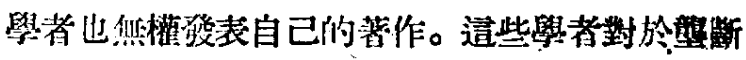

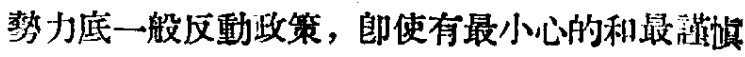
的反粼企圖，表示同情於進步思想，也會引起着立 刻扯毁任用契約、解聘或列入L黑名單7的危險。

第一切科學機整堷幹部、同時也是理論研 究中心的大學和專科學院，在美國科學研究網中， 起着重大的作用。但在美國流行的一種概念：各大

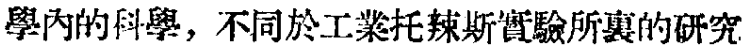

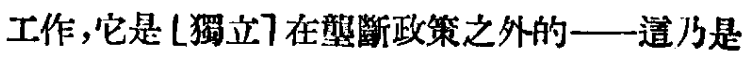
大大的竦解或有意的欺斒。

幾乎包括全部美國大學的學者游會控制着美 國二百假最大的團體，而這些拹會却是處在華爾 街底直接控制之下, 只要指壮趛一事暨, 䂨足够馀 明了。

熊斷勢力底影響又以無恥的露吊態度表現在

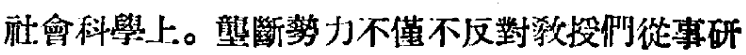
究常前問題, 相反地, 而是要求造愫做, 但附有條 件:遭種作業和敎授們底一切著作與言諭,都必須

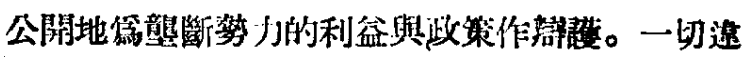
反這種政策的人，都低情地被捏仙學校。被視媱危 险份子。

各大學校長在執行主人底命令時，就當前迫 切的政治和經游润题，發表反動的言論，而道些言

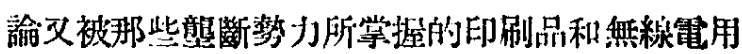
“來湢泛地傳播。

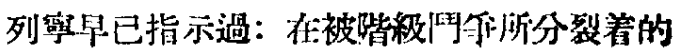

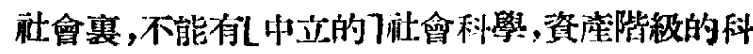

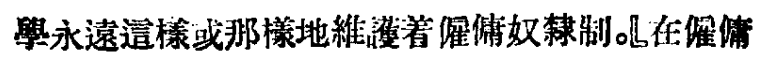

第一期

科量通報 
奴隸制底肚會中期待中立的科學, 是如同期待微 主激於可否诚低资本利潤以增拥工人工資問題探

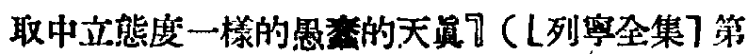
十九织,第三頁)。

現在，當美國成经了常國主義營量的主要力

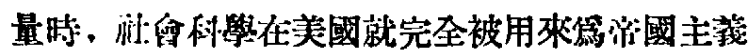
底擴張服彩。

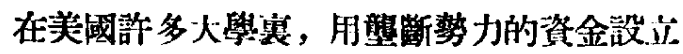

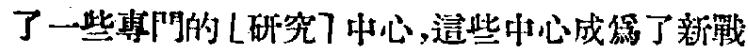

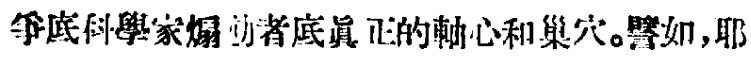
售大學國際佩題研究學院, 川是美國地理政治學

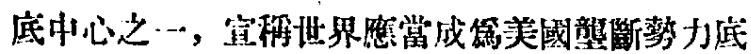

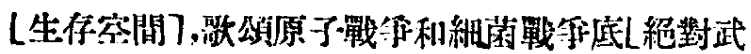
器7。

大部分遖接服務於资本主军托轱斯的美國程

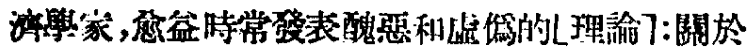
新的世界大戰底不可避免性，谌至希些新的世界

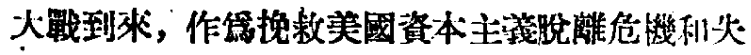

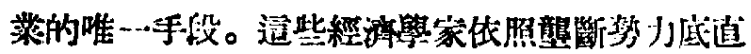
接命令，企圖使美國人民碓信增加軍背會L刺激桨

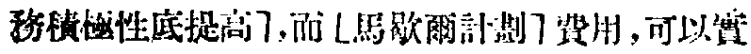

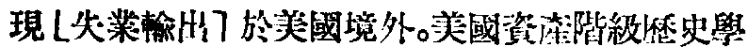
家焎耵地曲解著美國歴史和國際關係史，企圖把

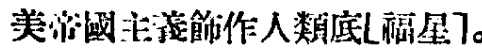

美國的學者一人種學家和社會學家，巧炒 地企圆把希特勤的種族論翻版成美國的色調，以

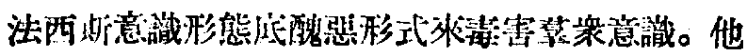

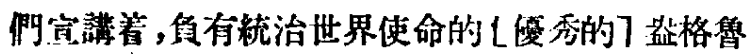

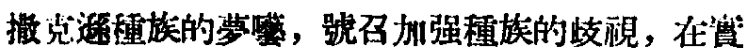
際上主張對黑人使用私刑、絕隇印第安人和殘酷 地制削殖民地人民。許多美國生物學家，從秘问

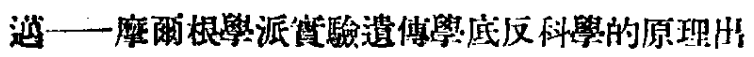

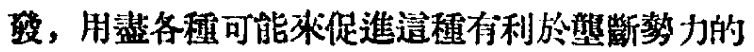
民仇䤄泟素底傅播。

近㙨年秝，美國政倠在對待所有進步的科學 力量方面，以日谷上人的碃枹性，表現它是暴力和 虚待底工具。

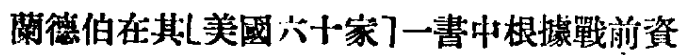
料所引證的進步學者被陮除和被迫害的例于，闹 現在統治者對於進步科學工作人具所施的種㮔反

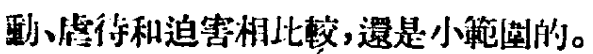

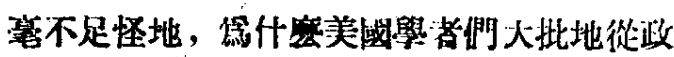

府職橪上逃跑掉，而被迫留在政府職挌上的學者 們，則在不壦忍受的思想恐惟中，或考像美國所惯 用的說法,在中世紀的 L捉拿女巫 7 的環境中生活 着和工作着。

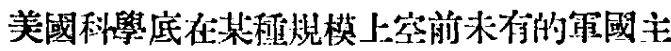

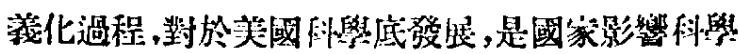
研究活動忞谷不诃避挽的絬果。

關於近年来政时用於科學研究工作上的背用 的官方資料，是美國科學軍國主義化底空前規㭖 底鮮明指墂。

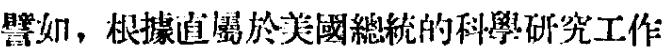

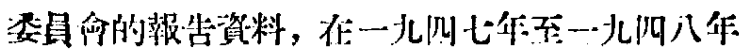

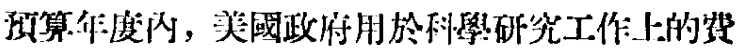

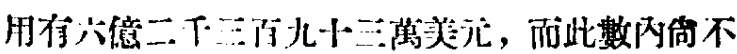
包括用於研究和試驗原丁武器工作的皆成。從上. 速總額山，游軍力面得到了二億公下二百萬美元 (仙百分之四十二)，掯軍方面得到了二億三十七

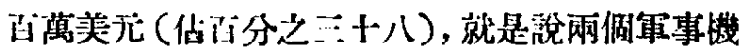
關一共支师了國家科學椠用總額底百分之八十。

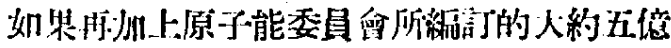

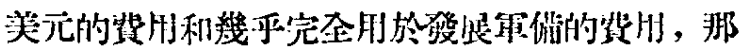

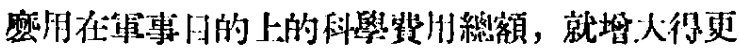
多了。

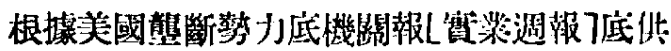

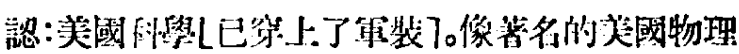

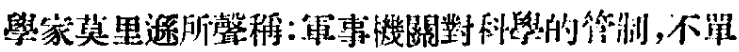

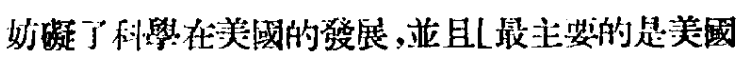
科學在企世界面前古當看更叮怕的新戰争底兵工。 蚛门。

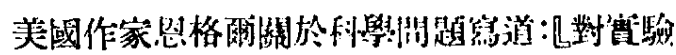

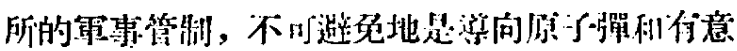

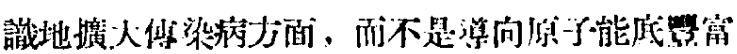

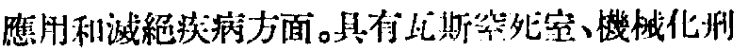

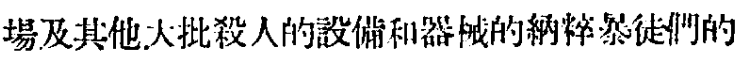

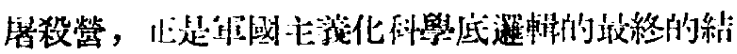

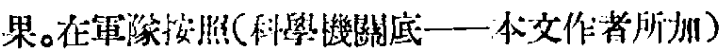
悵單付款後,您就能得到武器, 却得不到動力站战 特效整。?

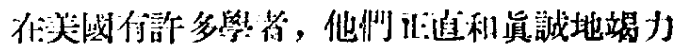

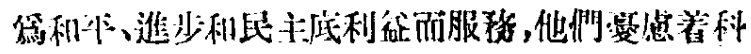

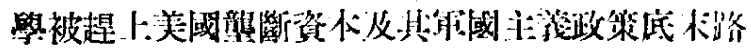

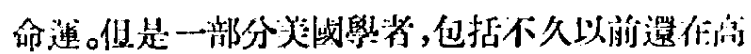




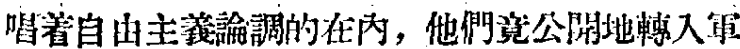

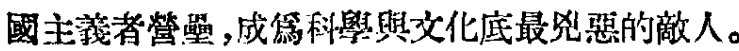
許多其他的美國學者，參與了〈世界國家７底世界

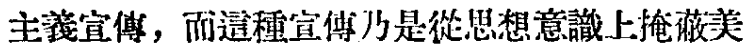

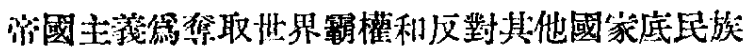
的主權和獨立的除謀。對於造點，他們不啃最下流 地以原子彈相恐啉和探用弯迫方法。物理學家尤

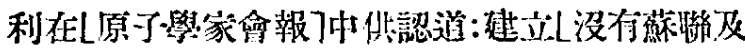
其他社會主義國家參为的世界國家7，就是說建立
在美國位護下的反蘇集團。

上列事實岄䫏地指任: 美國出版物，期於科 任美國的揑造的獨立與中立的胡說, 究有怎核的 㵋优。這些事賏證明着: 科學在美國越來越大地服

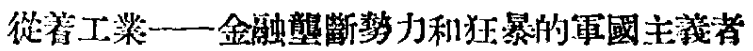

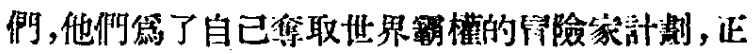
竭力利用着科學。(譯自一九四九年六月二十一日 蕉萂聯文化與生活報)
(.上接解 34 典)

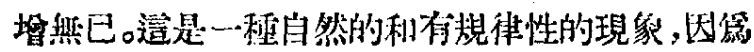

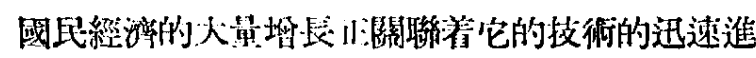

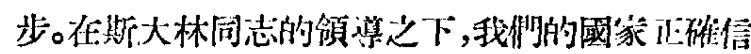

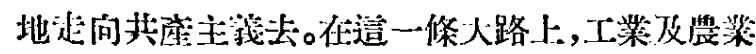
和過去相較, 更不可限量地需求着科學方面的支 嗳。一

勞動和科學的綃合，科學思想和生紊的結合， 並不综留在一偑地方，它正墢腿清，它也錯棕複

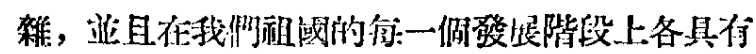

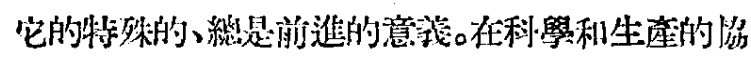

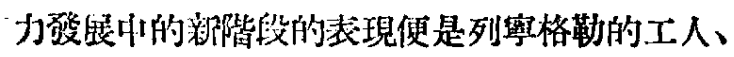

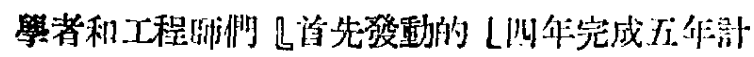

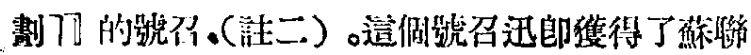

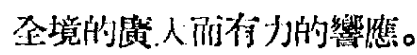

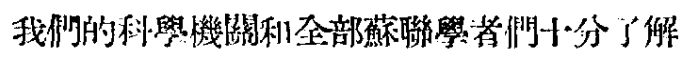
科學工作者們和察践的經常聯㢣的重要性。此地

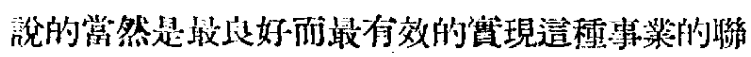
慗。前進的科學研究所和高敉學淮页䘞了很多對

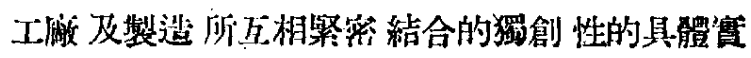
例。

科學利生成的聯繫形式可以有很多的方面。

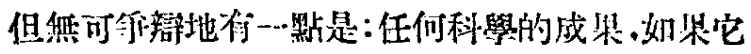

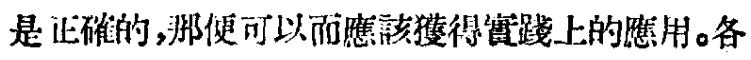
位正努力研究着筑人理諭上的開題的蘇維埃學者

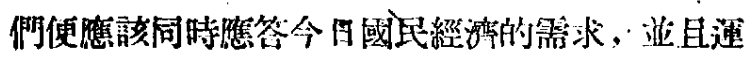

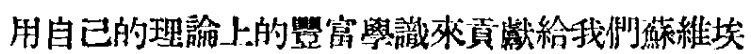
國家一些紫践情的結論。

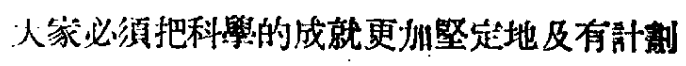
地深入到生產中去。同時在這㮯事落中時常會有

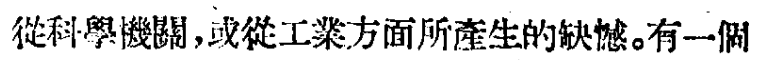
最可信賴的，使科舉成就深入到生产中去的正確 方法一一道就是科學機關和企業及费栄的直接聯 慗。

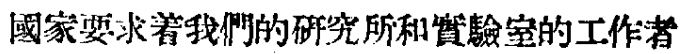

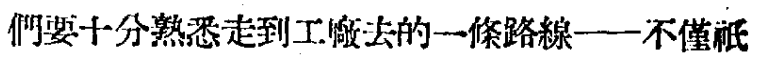
到管理的辦公空中去, 而且要到工場中歨。同時也 㴗求看相對的一佟路線一一從工澈到科學研究所 的路線一一這也是工程的、技術家和前進的斯增 合榙夫工作者們所應镃悉的路線。

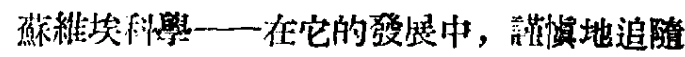

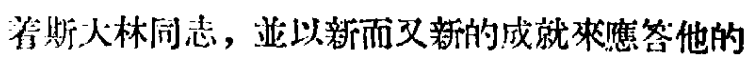

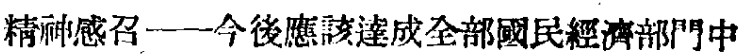

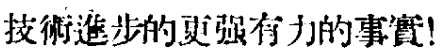

斯大林特代的勞動和斯人林時代的科學 團結藏葴!

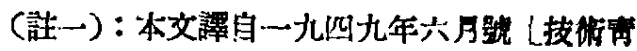

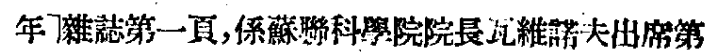

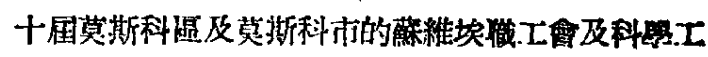
作者大會上的演請箁。

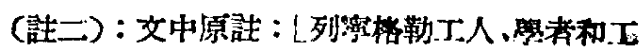

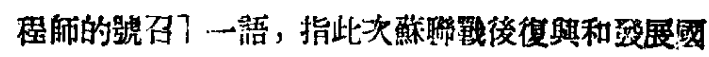

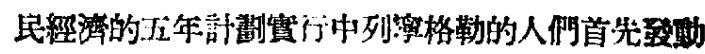

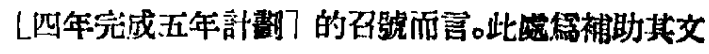
義, 特以括弧引入。 